\title{
GIANT CELL GRANULOMATA IN REGIONAL LYMPH NODES OF CARCINOMA
}

\author{
BY \\ G. A. GRESHAM AND A. G. ACKERLEY \\ From the Department of Pathology, University of Cambridge
}

(RECEIVED FOR PUBLICATION OCTOBER 19, 1957)

The occurrence of sarcoid-like lesions within neoplasms and in regional lymph nodes is now a well recognized phenomenon (Marshall, 1956). Examples of such lesions have been reported in association with a variety of tumours, for example, carcinoma of breast, skin, bronchus, and bile ducts, ovarian tumours, and neurocytoma (Refvem, 1954).

The association of generalized sarcoidosis with carcinoma is decidedly rare. Gherardi (1950) presented a case and was unable to find any other example in the literature up to that date: Symmers (1951) questions the authenticity of generalized sarcoidosis in Gherardi's case, as the necropsy was of limited extent.

The object of this paper is to present a case of carcinoma associated with generalized sarcoid lesions in lymph nodes and 10 cases of carcinoma in which the regional lymph nodes show diverse granulomata and giant cell reactions.

\section{Material and Methods}

The tissues examined were from surgical and necropsy material. Fixation was by formal saline, Heidenhain's Susa, or corrosive formal. All tissues showing giant cell lesions were stained by haematoxylin and eosin, Gordon-Sweets' method for reticulin fibres, Weigert's resorcin fuchsin and Ponceau $S$ for elastic tissue and collagen, and by Perls' method for haemosiderin.

\section{Case Reports}

Case 1 (P53/425). - T. H., a man aged 53, had a carcinoma of the stomach with generalized "sarcoid lesions."

This man had suffered epigastric pain after meals for five years before a gastro-enterostomy was done in 1941. His symptoms largely disappeared, but pain recurred in 1952. Vomiting occasionally accompanied the pain, but became more severe, and he was admitted to hospital for investigation in December, 1953.

Examination showed a rather thin, pale man ; there was some upper abdominal tenderness but no other important abnormality. The blood haemoglobin was $8.6 \mathrm{~g}$. per $100 \mathrm{ml}$. ; a barium meal showed a functioning gastro-enterostomy but no evidence of ulcer.

At laparotomy a large pyloric mass was found and a total gastrectomy was done. Post-operative convalescence was uneventful until. the tenth day when he suddenly collapsed and died.

A massive intraperitoneal haemorrhage was found at necropsy ; it arose from the site of oesophageal and jejunal anastomosis, although the vessel concerned was not identified. No evidence of metastasis was found, the only other abnormality being enlargement of the spleen $(615 \mathrm{~g}$.) and slight enlargement of lymph nodes in the neck, mediastinum, and abdomen.

Histology.-The surgical specimen was an acinar columnar cell carcinoma. Two lymph nodes from the lesser omentum contained metastases; one of these contained sarcoid-like lesions which were also seen in another node not involved by growth. The sarcoid-like lesions (Fig. 1) consisted of numerous discrete, rounded areas of eosinophilic histiocytes, the latter having ill-defined outlines; most of the cells were surrounded by a reticulin strand. Giant cells containing up to 40 nuclei, which were often peripheral in position, were found within the areas of histiocytes. Many giant cells contained clusters of globular inclusions (Fig. 2) and transitions between these and asteroid bodies could be found.

Sections of lymph nodes, lung, and liver, taken after $\frac{7}{0}$ death, showed histiocytes and giant cells mingled together with no follicular arrangement. The lymph ô nodes were diffusely involved by this process (Fig. 3) and many giant cells contained asteroids and globular bodies. There was some slight fibrosis throughout $\underset{\omega}{N}$ the node and each histiocyte was encircled with a 0 reticulin strand. The appearances agree with those considered by Robb-Smith (1938) and Cowdell (1954) to be characteristic of Stengel-Wolbach sclerosis. The sections of spleen showed no evidence of granulomatous lesions.

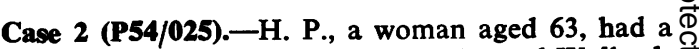
carcinoma of the thyroid and Stengel-Wolbach $\overrightarrow{\mathbb{D}}$ sclerosis.

This woman was admitted to hospital in December, 1953, for the investigation of low back pain which 8 


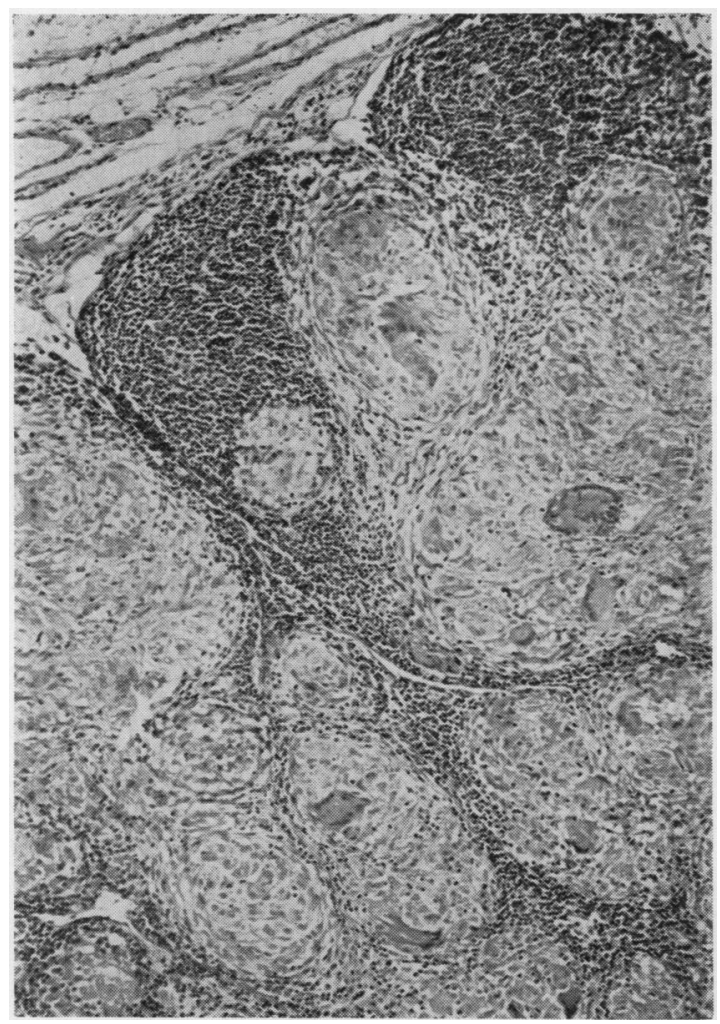

Fig. 1.-Sarcoid-like lesions in a lymph node from the lesser omentum (haematoxylin and eosin $\times 90$ ).

had been present for two months. On examination she was pale and a firm mass of lymph nodes was found in the left supraclavicular triangle. The blood haemoglobin was $11.4 \mathrm{~g}$. per $100 \mathrm{ml}$; ; no occult blood was detected in the faeces. A biopsy of the enlarged nodes showed that they were largely replaced by a polygonal cell carcinoma the source of which remained uncertain. She deteriorated rapidly following the biopsy and died.

Necropsy revealed a spherical white mass $(2 \mathrm{~cm}$. diameter) in the right lobe of the thyroid gland. A few small metastases were found in the lower lobes of both lungs; each pleural sac contained about $200 \mathrm{ml}$. of blood-stained fluid. Metastases were seen in the cut surface of the right femur, vertebrae, and sternum.

Cervical, mediastinal, coeliac, and other abdominal lymph nodes contained growth. One node alongside the abdominal aorta was enlarged but did not contain macroscopic growth. Nodules of growth were present in the liver. The spleen was rather small $(155 \mathrm{~g}$.) and had a purple-brown cut surface in which were slightly raised, rather ill-defined areas (approximately $1.5 \mathrm{~cm}$. diameter).

No important abnormality was found in any other organ.
Histology.-The thyroid nodule was a polygonal cell carcinoma; similar tumour tissue was found in sections of the liver, lungs, vertebrae, sternum, femur, and cervical and coel:ac lymph nodes. Numerous rounded follicles, composed of histiocytes with illdefined boundaries, were scattered throughout the section of spleen. Most of the follicles contained giant cells with globular inclusions; a few had asteroid inclusions (Fig. 4). Each follicle was surrounded by a delicate reticulin network and reticulin fibres passed radially into the follicles enclosing each histiocyte in a single strand. Some histiocytes contained haemosiderin and many of the follicles lay adjacent to clumps of haemosiderin pigment.

The para-aortic node contained scattered giart cells with globular or, less often, asteroid inclusions (Fig. 5). Very occasionally a giant cell showed anisotropic material. Follicles of histiocytes were not seen. A few sinuses were replaced by hyalinized fibrous tissue.

Case 3 (S49/2093).-A. H., a man aged 65, had a carcinoma of the tongue and a giant cell reaction in the cervical lymph nodes.

This man was first seen in May, 1949, with a small carcinomatous ulcer on the right side of the tongue

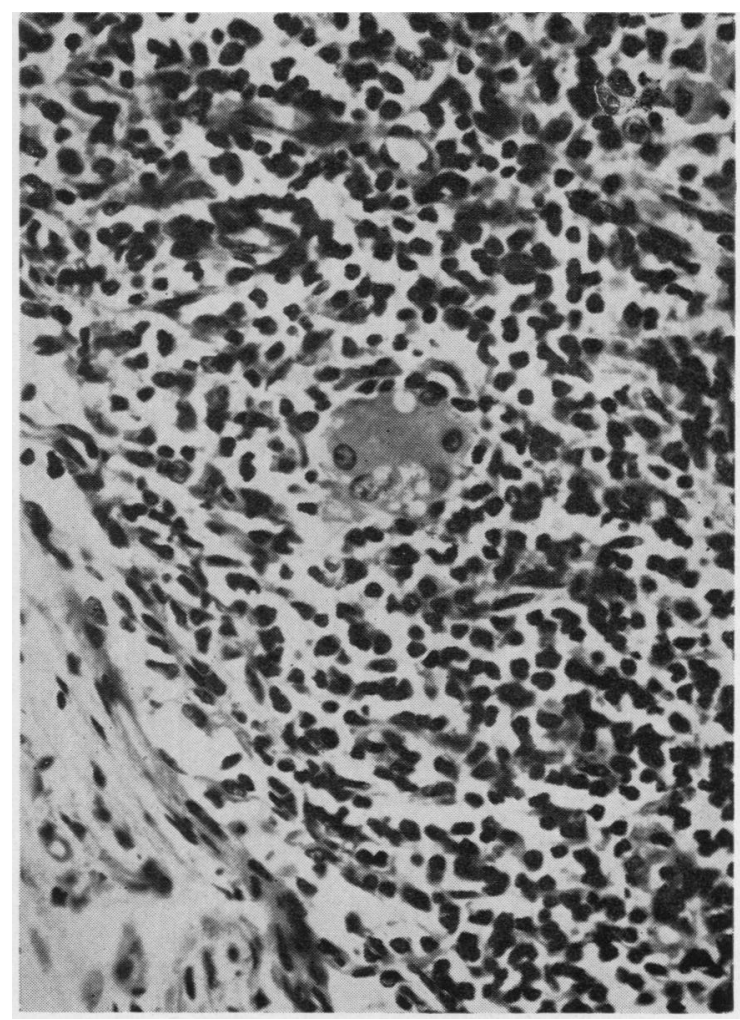

FIG. 2.-Globular inclusions in a giant cell (haematoxylin and eosin $\times 350$ ). 
which was treated by irradiation. The response was rot satisfactory and he was readmitted in August, 1949, when the carcinoma was excised and a block dissection of right cervical lymph nodes was done. Recovery has been uneventful and there is no evidence of recurrence.

Histology.-The tumour was a well differentiated squamous carcinoma. Three cervical lymph nodes contained growth ; in one of these clusters of giant cells, two of which contained globular inclusions, were present near the peripheral sinus. Rounded follicles of histiocytes were not conspicuous, though two areas in the node contained groups of histiocytes bounded by connective tissue suggesting a follicular arrangement. Reticulin fibres did not surround the histiocytes or the follicles themselves.

Case 4 (S54/4102). - A man aged 59 had a carcinoma of the stomach and sarcoid-like lesions in the omental lymph nodes.

This man was admitted to hospital in November, 1954, for the investigation of epigastric pain. A laparotomy was done and showed a carcinoma encircling the stomach about midway along its curvatures. A total gastrectomy was performed.

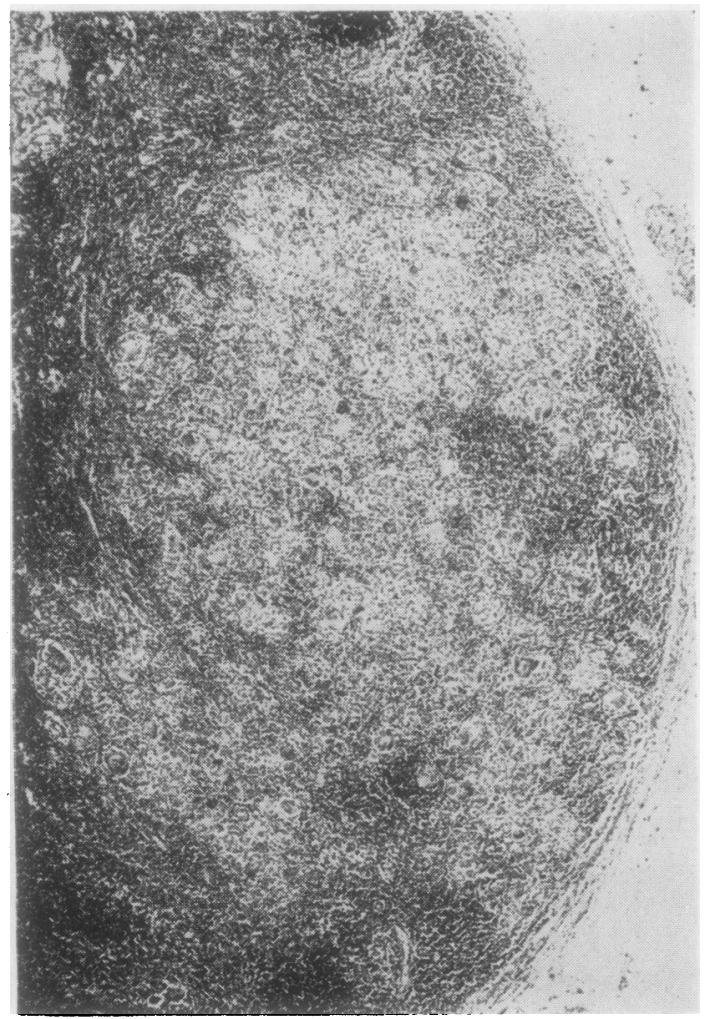

FIG. 3.-Diffuse mixture of histiocytes and giant cells in a lymph node (haematoxylin and eosin $\times 35$ ).

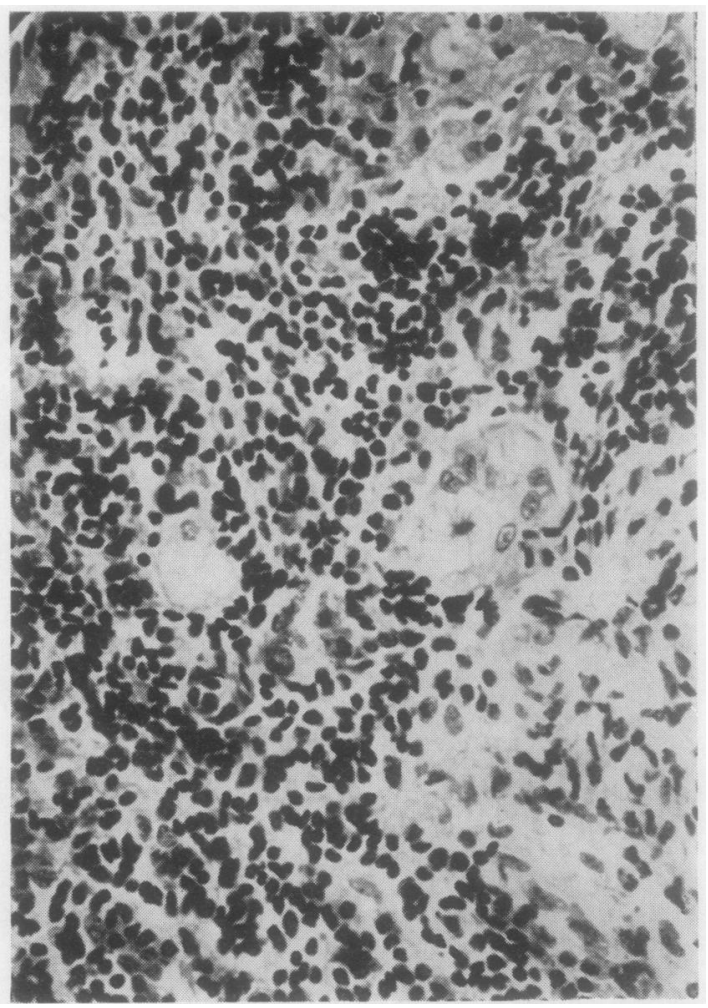

FIG. 4.-Asteroid and globular inclusions in a giant cell (haematoxylin and eosin $\times 350$ ).

Malignant ascites developed in August, 1955, the liver became enlarged, due to metastases, and he died. A necropsy was refused.

Histology.-The gastric tumour was a tubular cubical cell carcinoma. None of the lymph nodes sectioned contained growth; however, two from the lesser omentum contained peripheral follicles of histiocytes occasionally situated in the peripheral lymph sinus (Fig. 6). These follicles were composed of histiocytes with poorly defined boundaries ; fibrosis within or around the follicles was not a conspicuous feature, nor were reticulin fibres detected in or around them. Occasional giant cells without inclusions were found in the follicles.

Case 5 (S54/3238). -W. B., a man aged 50, had a malignant melanoma of the foot and "StengelWolbach lesions" in the inguinal lymph nodes.

This man was admitted to hospital in September, 1954, for removal of a melanoma of the right foot; a block dissection of the inguinal lymph nodes was done at the same time. He had not shown any clinical evidence of recurrence when last seen in February, 1956.

Histology.-The lesion on the foot was a malignant melanoma. Three of the 10 inguinal lymph nodes 
contained giant cells, with globular and asteroid inclusions, mingled with histiocytes which showed clearly defined cytoplasmic boundaries. The histiocytes were not grouped into a follicular arrangement, but these and the giant cells were surrounded by a strand of reticulin. Clumps of haemosiderin pigment were seen in the areas of giant cells. Fibrosis was not a conspicuous feature of these nodes. One of the remaining nodes contained a deposit of a malignant melanoma.

Case 6 (P54/403). - W. C., a man aged 54, had a carcinoma of the stomach with a giant cell reaction in omental lymph nodes containing growth.

This man was admitted to hospital in August, 1954, with a two-month history of pain and fullness in the epigastrium. An upper abdominal mass was felt on examination and a barium meal confirmed the clinical diagnosis of carcinoma of the stomach.

A total gastrectomy and splenectomy was done in September, 1954. He developed peritonitis and died nine days later.

Necropsy confirmed the diagnosis of peritonitis due to a leak from the oesophago-jejunal anastomosis; a left lower lobe bronchopneumonia was also present. No evidence of metastatic carcinoma was found at necropsy.

Histology.-The gastric tumour was a spheroidal cell mucus-producing carcinoma. Four lymph nodes taken from the lesser omentum were diffusely infiltrated by carcinoma cells; mingled with the tumour

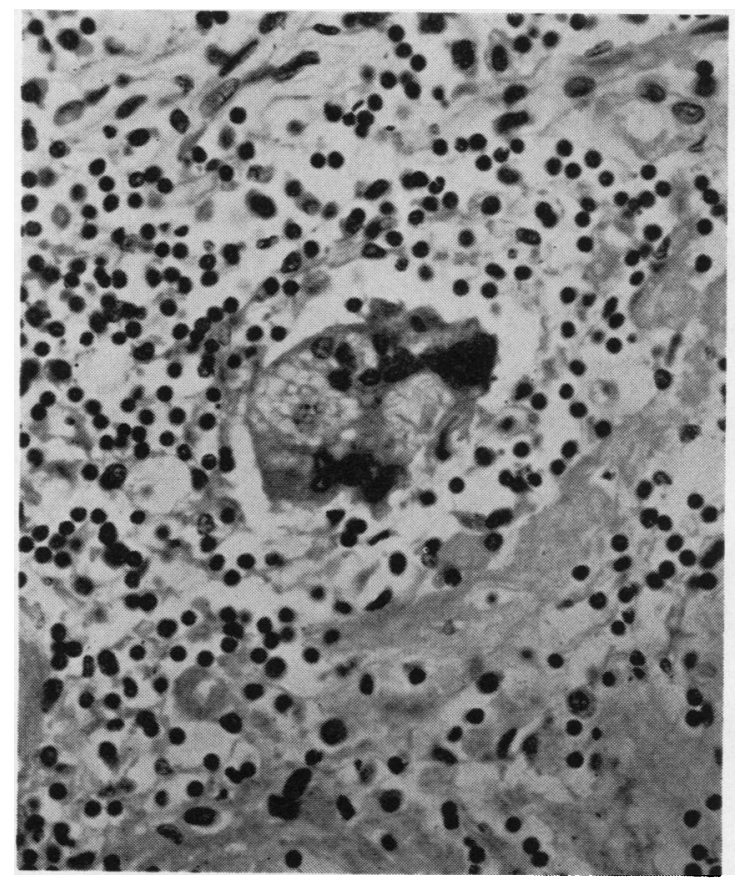

FIG. 5.-Globular inclusions in a giant cell (haematoxylin and eosin 350).

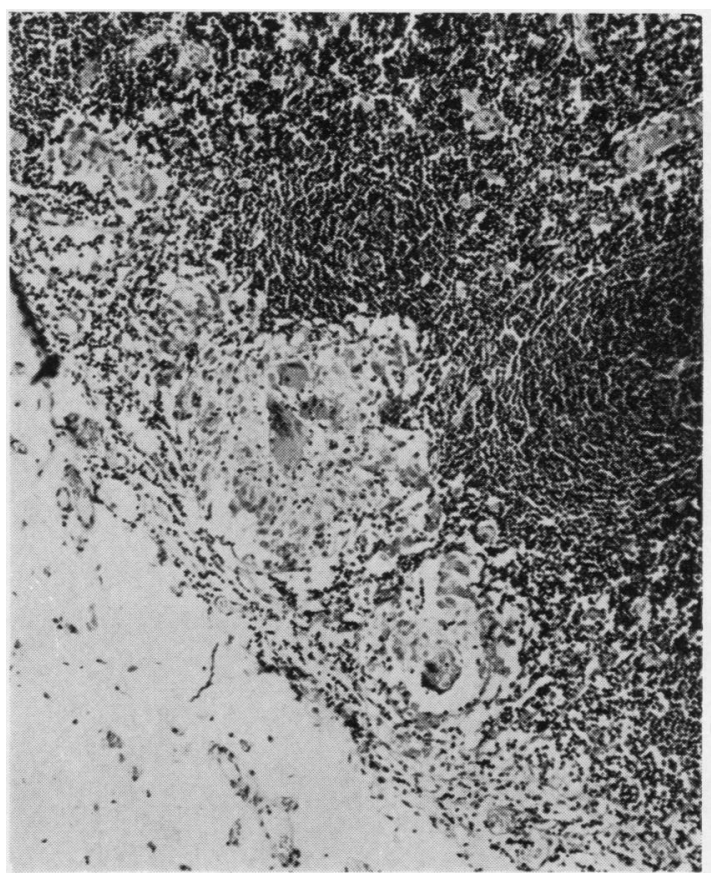

FIG. 6.-Peripheral lesions in a lymph node (haematoxylin and $\operatorname{eosin} \times 90)$.

cells were giant cells, some of which contained globular bodies (Fig. 7). The latter bodies did not stain pink with mucicarmine. Lymph nodes were examined, at necropsy, from the cervical, mediastinal, abdominal, inguinal, and axillary groups; none of these contained growth or giant cells.

Case 7 (S53/4551).-E. K., a woman aged 55, had a carcinoma of the stomach and a giant cell reaction in the neoplasm and in an omental lymph node.

This woman was admitted to hospital in October, 1953, for the investigation of epigastric pain. A carcinoma of the stomach was found at laparotomy and removed by a total gastrectomy. Convalescence was uneventful.

The liver was found to be enlarged and nodular in March, 1955. She was admitted to hospital in April, 1955, because of acute intestinal obstruction and died in a few hours. Necropsy was refused.

- Histology.-The gastric neoplasm was a diffusely infiltrating carcinoma. Foci of histiocytes with poorly defined boundaries were found in the circular muscle coat adjacent to the carcinoma (Fig. 8). A few giant cells were found in the follicles, but did not contain inclusions; a small amount of anisotropic material was found related to some of the giant cells. Two lymph nodes contained growth and in one of these was a follicle of histiocytes containing a few giant cells but no anisotropic material. Fibrosis was not a conspicuous feature of the follicles in the 


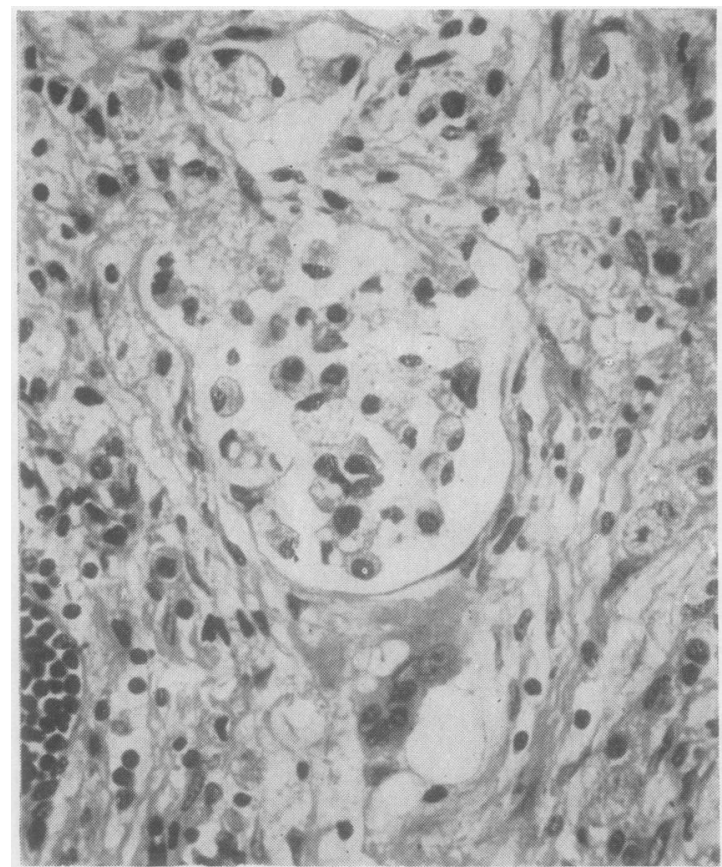

Fig. 7.-Giant cell, containing globular inclusions, adjacent to tumour cells (haematoxylin and eosin $\times 350$ ).

stomach or the lymph node, though each histiocyte and giant cell was surrounded by a reticulin strand.

Case 8 (S54/1398).-F. D., a woman aged 28, had a carcinoma of the cervix with a giant cell reaction in an iliac lymph node.

This woman was admitted to hospital in March, 1954, for the investigation of a vaginal discharge. A carcinoma of the cervix was found on examination and treated by the insertion of radium. Post-radiation biopsies showed persistent viable growth and a Wertheim's hysterectomy was done in April, 1954. The iliac lymph nodes which were removed did not appear to contain growth macroscopically.

The patient left the country and has not been seen subsequently.

Histology.-The cervical tumour was a poorly differentiated epidermoid carcinoma. None of the iliac lymph nodes sectioned contained growth, but one of them showed a cluster of histiocytes and a few giant cells, without inclusions, near the periphery. There was no fibrosis in the node.

Case 9 (S54/1439). - K. S., a woman aged 51, had a carcinoma of the parotid gland with a giant cell reaction in a regional lymph node.

This woman was admitted to hospital in April, 1954, complaining of a lump in the region of the left parotid gland. Biopsy showed it to be a carcinoma. A course of $x$-radiation was given followed by removal of the entire parotid gland.
She was readmitted in June, 1955, because of recurrence of swelling at the operation site; this was removed and found, on histological examination, to be a lymph node. She subsequently developed widespread metastases and died at home. A necropsy was not obtained.

Histology.-The neoplasm in the parotid was a poorly differentiated carcinoma. The lymph node. removed in June, 1955, was infiltrated by sheets of polygonal carcinoma cells separated by strands of hyaline fibrous tissue ; many vessels showed intimal fibrous thickening. Occasional ill-defined follicles of histiocytes were seen, containing giant cells, some of which had anisotropic material in the cytoplasm. Reticulin strands extended around the histiocytes and giant cells.

Case 10 (P56/478). - J. S., a man aged 64, had a carcinoma of the pinna with a giant cell reaction in the regional lymph nodes.

This man was first seen in 1953 with a carcinoma of the left pinna which had been present for five years. He refused operation and was treated by radiotherapy. The lesion recurred and he agreed to removal of the left pinna in May, 1954. The lesion recurred on two further occasions in November, 1954, and September. 1955 ; the growth was excised on both occasions. A block dissection of enlarged cervical lymph nodes was done in July, 1956. Recurrence of growth and infec-

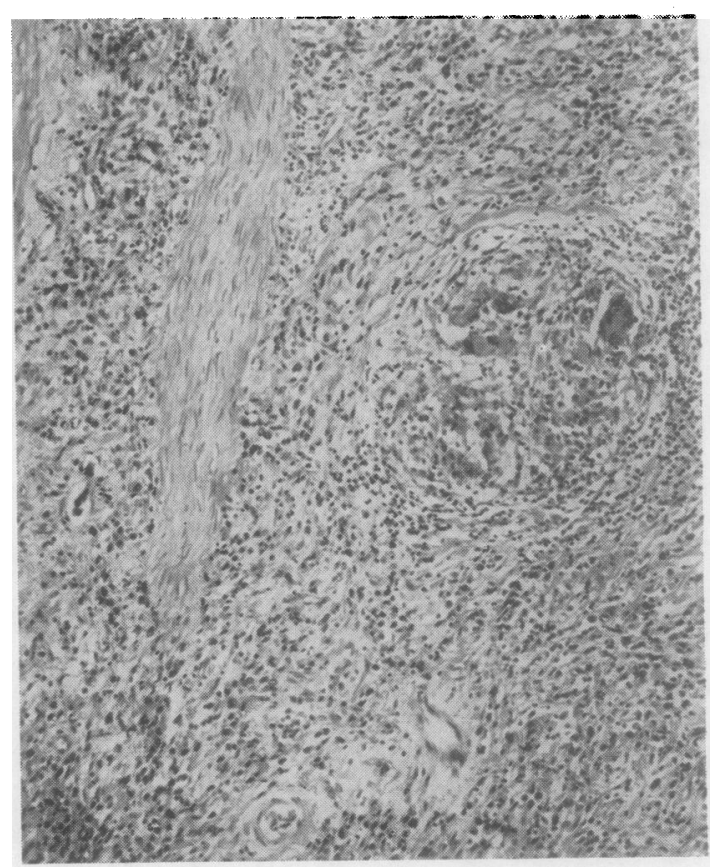

Fig. 8.-Circumscribed lesion in stomach wall (haematoxylin and eosin $\times 90$ ). 


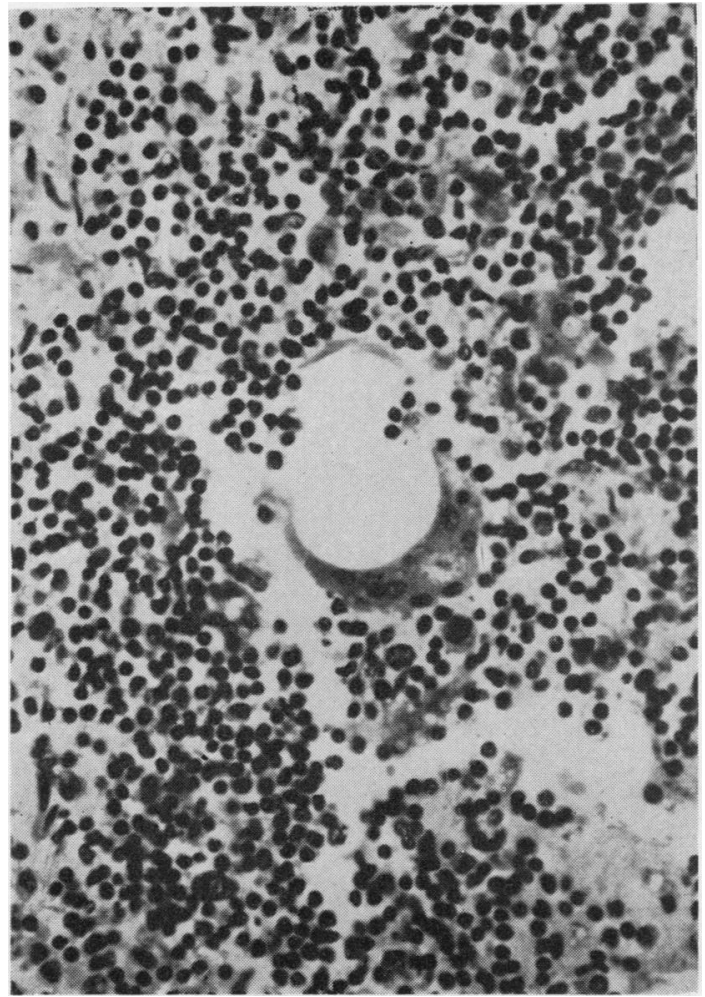

Fig. 9.-Giant cell with asteroid inclusion (haematoxylin and eosin $\times 350$ ).

tion occurred at the site of excision of the primary and secondary neoplasms; he developed bronchopneumonia and died in December, 1956.

Necropsy showed masses of firm white growth around the left external auditory meatus and extending downwards to surround the carotid arteries and medially involving the transverse processes of three upper cervical vertebrae. Growth was seen macroscopically in left and right cervical and mediastinal lymph nodes. Small metastases were present in the lower lobes of both lungs, which also showed areas of bronchopneumonia. No metastases were found elsewhere.

Histology.-Ten lymph nodes removed in June, 1956, all contained numerous rounded collections of histiocytes and giant cells; inclusions were not seen in the latter. A few strands of fibrous tissue were present around the follicles, but reticulin fibres did not extend between the histiocytes in the follicles. An occasional follicle showed a slight degree of central necrosis and haemosiderin was present, situated near to the follicles in many of the nodes. Numerous lymph nodes were taken at necropsy from the neck, thorax, axillae, and abdomen. Some contained growth, but none contained giant cell lesions.
Case 11 (P55/216). -J. M., a man aged 59, had a giant cell reaction in an omental lymph node which was an incidental finding at necropsy.

This man suddenly collapsed and died. Necropsy revealed a myocardial infarct due to coronary thrombosis. A slightly enlarged lymph node was noted in the lesser omentum; other nodes and the spleen were normal.

Histology. - Numerous giant cells containing asteroids and globular bodies were seen in the sinuses throughout the node (Fig. 9). There was no histiocytic proliferation nor was there any fibrosis.

\section{Discussion}

Granulomatous lesions, histologically similar to those seen in sarcoidosis, have been reported in association with carcinoma (Wolbach, 1911; Gherardi, 1950; Nadel and Ackerman, 1950 ; Symmers, 1951; ten Seldam, 1956). Cowdell (1954) discusses such lesions in the differential diagnosis of sarcoidosis. Collections of epithelioid and giant cells are frequently found in the ovarian disgerminoma (Schiller, 1934; Föderl, 1938; Sailer, 1940), and occasionally in granulosa cell tumours (Schattenberg and Harris, 1946). Sailer (1940) has reviewed the theories of origin of such lesions, which are tuberculosis, a stromal reaction to disintegrating tumour cells, or that they may be derived from the neoplastic cells.

The association of sarcoidosis with malignant neoplasm is rare ; Case 1 could be an example of this. There are, however, certain features of this case which are not in agreement with a diagnosis of sarcoidosis. There are histological differences between the lesions in the gastric nodes, which resemble those of sarcoidosis, and those in the lung, liver, and other lymph nodes which conform to the criteria of Stengel-Wolbach sclerosis. The spleen was not involved; this makes a diagnosis of Stengel-Wolbach sclerosis or sarcoidosis improbable. Case 1, therefore, could either be a widespread granulomatous reaction to carcinoma of the stomach and its products, or else the coexistence of a gastric neoplasm and sarcoidosis. It seems unlikely that Stengel-Wolbach sclerosis can be considered to be histologically distinct from sarcoidosis. In Case 1, lesions which resembled sarcoid and Stengel-Wolbach sclerosis were found. The lesions in regional nodes from Case 5 were also of Stengel-Wolbach type, but no other evidence of this disease was present.

The remarkable localization of lesions, resembling Stengel-Wolbach sclerosis, to the spleen and para-aortic lymph node in Case 2 makes a diagnosis of Stengel-Wolbach sclerosis improbable. 
It seems more likely that those in the spleen were due to related clumps of haemosiderin or anisotropic material which was also present in some giant cells in the lymph node; Refvem (1954) reports sarcoid-like lesions produced by injection of blood. The lesions in Cases 5 and 10 may also be due to haemosiderin. Marshall (1956) has suggested that lesions seen in sarcoidosis and StengelWolbach sclerosis are variants of the same disease process. Furthermore, the findings in these cases suggest that both types of lesions may also occur as a tissue response to such agents as blood (Cases 2, 5, and 10), foreign material (Cases 2, 7, and 9), and products of necrosis of neoplasms (Cases 1, 3,4 , and 8).

No obvious cause was found for the lesions in the involved lymph node taken from the abdomen of Case 11. Four other cases in this paper showed lesions in abdominal nodes, and, though this may be coincidental, the possibility remains that foreign material or blood may make its way through minor breaches in the mucosa of the gut and cause such lesions in lymph nodes. The finding of sarcoidlike lesions, related to foreign material, in regional lymph nodes from Crohn's disease lends support to this view. However, a survey of the regional nodes from 50 cases of gastric ulcer examined in this laboratory over the past year failed to show any such lesions; this may be partly due to the smaller number of lymph nodes sectioned as compared to those examined in gastric carcinoma and partly to the restriction of this type of tissue reaction to certain individuals.

In Cases 3, 4, and 9 lesions were seen in the peripheral sinus of the nodes: this suggests that the exciting factor may be transported by the lymph stream. Symmers (1951) supports this view, though he reports the frequent finding of lesions near the hilum of the nodes. In Cases 3 and 8 the regional nodes and the neoplasm itself had been treated with $x$ rays ; this, no doubt, contributed to the amount of necrotic material reaching the nodes.

Asteroid or globular inclusions, in giant cells, cannot be considered to be diagnostic of either Stengel-Wolbach sclerosis or sarcoidosis. Goldmann (1890) illustrates an asteroid body in a giant cell found in a retro-auricular dermoid cyst, and Wolbach (1911) found such inclusions in giant cells in lymph nodes related to carcinoma. The origin of asteroids from globular inclusions was suggested by Friedman (1944), who found both to have similar histochemical properties. Teilum (1949) made the observation that Schaumann bodies were also closely allied histochemically to asteroid inclusions and postulated the asteroid as the precursor of the double contoured bodies of Schaumann.

The presence of asteroid and globular inclusions in the nodes from Cases 1, 2, 5, and 11, and of globular inclusions alone in Cases 3 and 6, suggests that they are non-specific structures which cannot be considered as unique features of any one disease process.

The cases reported in this paper illustrate a variety of granulomatous reactions in lymph nodes related to, or distant from, malignant neoplasms. The histological appearances resemble sarcoidosis in some, Stengel-Wolbach sclerosis in others; in the remainder the lesions are not reminiscent of either. This diversity may in part be due to the neoplasm; in this series gastric carcinoma is a factor in four cases. Another factor may be host idiosyncrasy.

The findings emphasize the fact that sarcoidosis is a disease entity, not a histological one, a point which must be borne in mind when assessing the value of conjunctival, scalene node biopsy (ten Seldam, 1956) and other forms of biopsy as an aid to its diagnosis.

\section{Summary}

Eleven cases are presented in which lymph nodes and sometimes other organs show histological features resembling sarcoidosis or StengelWolbach sclerosis.

In all but one case a malignant neoplasm is present.

The histological features are discussed.

We are grateful to Dr. A. M. Barrett for his encouragement and advice and for permission to utilize the histological material. The consultant staff of Addenbrooke's Hospital kindly allowed access to the case histories. Mr. S. W. Patman prepared the photographs.

\section{REFERENCES}

Cowdell, R. H. (1954). Quart. J. Med., 23, 29.

Föderl, V. (1938). Arch. Gynäk., 165, 392.

Friedman, M. (1944). Amer. J. Path., 20, 621.

Gherardi, G. J. (1950). Arch. Path. (Chicago), 49, 163.

Goldmann, E. E. (1890). Beitr. path. Anat., 7, 553.

Marshall, A. H. E. (1956). An Outline of the Cytology and Pathology of the Reticular Tissue, p. 141. Oliver and Boyd, Edinburgh.

Nadel, E. M., and Ackerman, L. V. (1950). Amer. J. clin. Path., 20, 952.

Refvem, O. (1954). Acta med. scand., Suppl. 294.

Robb-Smith, A. H. T. (1938). J. Path. Bact., 47, 457.

Sailer, S. (1940). Amer. J. Cancer, 38, 473.

Schattenberg, H. J., and Harris, W. H. (1946). Amer. J. Path. 22, 539 .

Schiller, W. (1934). Arch. Gynäk., 156, 513.

Seldam, R. E. J. ten (1956). Med. J. Aust., 1, 916.

Symmers, W. St. C. (1951). Amer. J. Path., 27, 493.

Teilum, G. (1949). Ibid., $25,85$.

Wolbach, S. B. (1911). J. med. Res., $24,243$. 